\title{
Resposta de pastagens perenes à adubação com chorume suíno: pastagem natural
}

\author{
Simone Meredith Scheffer-Basso ${ }^{1}$, Clênio Valdeni Scherer ${ }^{2}$, Marcelo de Faria Ellwanger ${ }^{3}$ \\ ${ }^{1}$ Universidade de Passo Fundo. Bairro São José, BR 285, Passo Fundo, RS. CEP: 99001-970. Bolsista CNPq. \\ 2 Zootecnista, Especialista, Técnico da Avipal. \\ ${ }^{3}$ Médico Veterinário, Especialista, Secretaria da Agricultura de São Sepé, RS.
}

RESUMO - Este trabalho foi realizado com o objetivo de verificar a resposta de uma pastagem natural na Depressão Central do Rio Grande do Sul à adubação com chorume suíno nas doses de 0, 15, 30 e 45 m³/ha, equivalentes a 76,8; 153,7 e $230,5 \mathrm{~kg} \mathrm{~N} / \mathrm{ha} /$ corte depois de cada um dos quatro cortes, realizados no período de outubro de 2003 e fevereiro de 2004 , totalizando 0, 60, 120 e $180 \mathrm{~m}^{3} / \mathrm{ha}$ de chorume. A massa seca (MS) da pastagem aumentou de forma linear de acordo com as doses de chorume. Na pastagem testemunha, com aplicação de $45 \mathrm{~m}^{3} / \mathrm{ha} /$ corte, houve aumento de $108 \%$ na produção de MS (1.137 kg/ha/corte; $4.549 \mathrm{~kg} / \mathrm{ha}$ no total dos cortes) e de $42 \%$ na altura da pastagem $(21 \mathrm{~cm})$ e redução de $8 \%$ no conteúdo de fibra em detergente ácido (FDA) (41,8\%). A eficiência da aplicação do chorume foi, em média, de 16,9 kg MS/m³/corte. Com as aplicações do fertilizante, verificou-se aumento na concentração de nutrientes no solo (máximo: $\mathrm{K}=200 \mathrm{mg} / \mathrm{L}$; $\mathrm{P}=52 \mathrm{mg} / \mathrm{L} ; \mathrm{Ca}=1,8 \mathrm{cmol}_{\mathrm{c}} / \mathrm{dm}^{-3} ; \mathrm{Mg}=1,4 \mathrm{cmol}_{\mathrm{c}} / \mathrm{dm}^{-3}$ ). A dose de $30 \mathrm{~m}^{3} / \mathrm{ha} /$ corte pode ser um valor-referência para as pastagens naturais na primavera-verão.

Palavras-chave: composição química, dejetos, nitrogênio

\section{Response of perennial pasture to fertilization with pig slurry: natural pasture}

\begin{abstract}
The work had the objective to verify the response of a natural pasture, in the "Depressão Central of Rio Grande do Sul”, Brazil, to pig slurry fertilization, in the doses of 0, 15, 30 and $45 \mathrm{~m}^{3}$ /ha, equivalent to total application of $0,76.5,153.3$, and $230.5 \mathrm{~kg} \mathrm{~N} / \mathrm{ha} /$ cutting of $\mathrm{N}$ after each one of the four cuttings, between October/03 and February/04, totalizing $0,60,120$, and $180 \mathrm{~m}^{3} / \mathrm{ha}$ of slurry. There was a linear increase of dry matter (DM) as function of pig slurry application. Compared to the control treatment, application of $45 \mathrm{~m}^{3} / \mathrm{ha} /$ cutting resulted in: a) $108 \%$ increase in the DM production (1.137 kg/ha/cutting; $4.549 \mathrm{~kg} / \mathrm{ha}$ in total of the cuttings) and $42 \%$ in the pasture height $(21 \mathrm{~cm})$; b) $8 \% \mathrm{decrease}$ in the ADF concentration (41.8\%). The pig slurry application efficiency was, on average, $16.9 \mathrm{~kg} \mathrm{DM} / \mathrm{m}^{3} /$ cutting. There was addition of soil chemical elements with fertilizer application, reaching a maximum of $\mathrm{K}=200 \mathrm{mg} / \mathrm{L} ; \mathrm{P}=52 \mathrm{mg} / \mathrm{L}$; $\mathrm{Ca}=1,8 \mathrm{cmol} / \mathrm{dm}^{-3} ; \mathrm{Mg}=1,4 \mathrm{cmol}_{\mathrm{c}} / \mathrm{dm}$. The $30 \mathrm{~m}^{3} / \mathrm{ha} /$ cutting can be a reference-value for the natural pasture in the springsummer.
\end{abstract}

Key Words: chemical composition, manure, nitrogen

\section{Introdução}

A produção de suínos em sistema de criação intensivo no Rio Grande do Sul teve um grande crescimento nas últimas décadas. Esses sistemas caracterizam-se pelo confinamento dos animais e resulta em grande volume de dejetos líquidos, denominados chorume, um composto orgânico com elevado potencial fertilizante, constituído de fezes, urina, sobras de ração, água e outros resíduos. Quando adequadamente armazenados e corretamente utilizados, esses dejetos podem fornecer nutrientes para as plantas e ainda melhorar consideravelmente as condições físico-químicas do solo. Essa é uma das alternativas de maior receptividade pelos agricultores por ser de fácil operacionalidade na propriedade (Seganfredo, 1999).

No Sul do Brasil, grandes extensões de terra são ocupadas por pastagens naturais, cujos solos geralmente são ácidos, com baixa disponibilidade de nutrientes e altos teores de alumínio em solução (Ceretta et al., 2003). Normalmente, os pecuaristas não fertilizam essas pastagens, o que têm resultado em baixos índices de produtividade (50 kg peso vivo/ha/ano). Entretanto, com práticas de adubação, introdução de espécies e ajuste de carga animal, é possível elevar esse índice para 500-600 kg PV/ha/ano 
(Maraschin \& Jacques, 1993). Os dejetos suínos poderiam ser uma alternativa para melhoria da fertilidade do solo, desde que sob manejo criterioso e com base científica.

No último censo agropecuário (IBGE, 2007), realizado em 1995-1996, foram apontados mais de 27 milhões de estabelecimentos com atividade na suinocultura no Brasil. Somente a Região Sul do país é detentora de 60 a $70 \%$ da produção de suínos e aves, o que gera produção de 450 milhões de dejetos por ano (Konzen, 2003). Assim, o uso do chorume em locais próximos às unidades de criação pode ser uma forma de aumentar a produção das pastagens, além de agregar nutrientes e matéria orgânica (MO) no solo. A adubação com dejeto animal aumenta os teores de matéria orgânica e melhora a estrutura do solo aumentando a capacidade de retenção de umidade, infiltração da água da chuva, atividade microbiana e capacidade de troca de cátions, solubilizando ou complexando alguns metais tóxicos ou essenciais às plantas, como $\mathrm{Fe}, \mathrm{Zn}, \mathrm{Mn}, \mathrm{Cu}$ e $\mathrm{Co} . \mathrm{O}$ rendimento das culturas, no entanto, depende da origem dos dejetos e da dose utilizada, de modo que a adubação com chorume suíno tem efeito imediato superior ao dos dejetos de bovinos, em virtude de seu potencial fertilizante, especialmente em relação aos teores de nitrogênio e fós foro.

O nitrogênio é um dos principais constituintes do esterco líquido de suínos e $50 \%$ desse nutriente é encontrado na forma mineral; ao ser aplicado, tem efeito imediato no crescimento das plantas (Ceretta et al., 2003). A Sociedade Brasileira de Ciência do Solo (2004) indica índice de disponibilização de 0,8 para o nitrogênio de dejetos suínos no primeiro cultivo. Edmeades (2003), em revisão sobre o uso de adubos orgânicos, destacou que os solos adubados com chorume, esterco ou resíduo vegetal apresentaram maiores conteúdos de matéria orgânica, maior atividade da microfauna, porosidade, estabilidade de agregados e condutividade hidráulica em comparação a solos adubados com fertilizantes minerais.

Em um dos poucos estudos com esse enfoque em pastagens nativas, Durigon et al. (2002), com doses de chorume suíno de 20 e $40 \mathrm{~m}^{3} / \mathrm{ha}$, observaram aumento de 44 e $70 \%$ na produção de MS em relação à pastagem sem adubação. Konzen (2003) destacou a resposta obtida por Barnabé (2001), no centro do país, com aumento de $156 \%$ na produção de MS de Brachiaria brizantha (A. Rich.) Stapf, com aplicação de dejetos suínos $\left(150 \mathrm{~m}^{3} / \mathrm{ha}\right)$, em relação à testemunha, e de $98 \%$ em comparação à adubação química. Recentemente, Medeiros et al. (2007) concluíram que a aplicação de dejetos líquidos de suínos (180 $\left.\mathrm{m}^{-3} / \mathrm{ha} / \mathrm{ano}\right)$ fermentados ou in natura possibilita produção de MS do capim-marandu (Brachiaria bizanthacv. Marandu) similar à obtida com adubo mineral.

Este trabalho foi realizado com o objetivo de avaliar a resposta de uma pastagem natural na região da Depressão Central do Rio Grande do Sul à aplicação de chorume suíno com a finalidade de aumentar o número de informações sobre o assunto e sugerir um valor-referência para adubação com esse fertilizante.

\section{Material e Métodos}

O experimento foi conduzido na Fazenda Timbaúva, em São Sepé, Rio Grande do Sul, no período de outubro de 2003 a abril de 2004, em área plana, com pastagem natural formada por Paspalum spp. e Axonopus spp. no seu estrato inferior. O município se localiza a $30^{\circ} 10^{\prime} \mathrm{S}$ e $53^{\circ} 33^{\prime} \mathrm{O}$, em altitude de $85 \mathrm{~m}$, na região fisiográfica da Depressão Central. O clima (Figura 1) é subtropical úmido, tipo Cfa2, conforme classificação de Köppen (Moreno, 1961). O solo pertence à Unidade de Mapeamento Vacacaí e caracteriza-se por uma textura superficial franco-arenosa no horizonte A e baixo teor de MO. Na implantação do ensaio, o solo apresentava as seguintes características físico-químicas: argila $=11 \%$, $\mathrm{pH}=5,2 ; \mathrm{P}=5 \mathrm{mg} / \mathrm{dm}^{3} ; \mathrm{K}=76 \mathrm{mg} / \mathrm{dm}^{3} ;$ matéria orgânica $=$ $1,30 \% ; \mathrm{Al}=0,4 \mathrm{Cmol}_{\mathrm{c}} / \mathrm{dm}^{3} ; \mathrm{Ca}=0,8 \mathrm{Cmol}_{\mathrm{c}} / \mathrm{dm}^{3} ; \mathrm{Mg}=$ $0,9 \mathrm{Cmol}_{\mathrm{c}} / \mathrm{dm}^{3} ; \mathrm{H}+\mathrm{Al}=3,50 \mathrm{Cmol}_{\mathrm{c}} / \mathrm{dm}^{3}, \mathrm{CTC}=5,30 \mathrm{Cmol}_{\mathrm{c}} / \mathrm{dm}^{3}$; saturação de bases $=35 \%$; saturação de $\mathrm{Al}=18 \%$. Em 24/11/2003, após roçada de emparelhamento, foi realizada aplicação de calcário dolomítico ( $2 \mathrm{t} / \mathrm{ha})$, juntamente com $\mathrm{P}_{2} \mathrm{O}_{5}(110 \mathrm{~kg} / \mathrm{ha})$ na forma de superfosfato triplo e $\mathrm{K}_{2} \mathrm{O}$ $(80 \mathrm{~kg} / \mathrm{ha})$ na forma de cloreto de potássio.

Procedeu-se à comparação de quatro doses de chorume suíno como fonte de nitrogênio em substituição à uréia. $\mathrm{O}$ chorume foi aplicado depois de cada corte da pastagem: D0 = ausência de chorume, D15 = $15 \mathrm{~m} 3 / \mathrm{ha}, \mathrm{D} 30=30 \mathrm{~m}^{3} / \mathrm{ha}$ e D45 = $45 \mathrm{~m} 3 / \mathrm{ha}$. Os tratamentos foram alocados em delineamento de blocos casualizados com quatro repetições. As parcelas mediram $18 \mathrm{~m}^{2}(6 \times 3 \mathrm{~m})$, distantes $1,5 \mathrm{~m}$ entre si. $\mathrm{O}$ chorume foi obtido na mesma propriedade, de uma unidade de terminação de suínos em regime de confinamento total. Os dejetos foram armazenados em bioesterqueiras abertas revestidas com manta asfáltica de $8 \mathrm{~mm}$ de espessura. Antes de iniciar os trabalhos de campo, foram coletadas amostras dos dejetos para análise, na qual foram observadas as seguintes características químico-físicas: $\mathrm{N}=0,50 \% ; \mathrm{P}_{2} \mathrm{O}_{5}=$ $0,37 \% ; \mathrm{K}_{2} \mathrm{O}=0,30 \% ; \mathrm{pH}=7,7$ e densidade média de 1.025 a $1.026 \mathrm{~kg} / \mathrm{m}^{3}$, contendo $5,11 \mathrm{~kg} / \mathrm{m}^{3}$ de N. Para as doses de $15,30 \mathrm{e} 45 \mathrm{~m}^{3} / \mathrm{ha}$, o nitrogênio aplicado equivaleu a aproximadamente 76,8; 153,7 e 230,5 kg/ha/corte. Considerando 


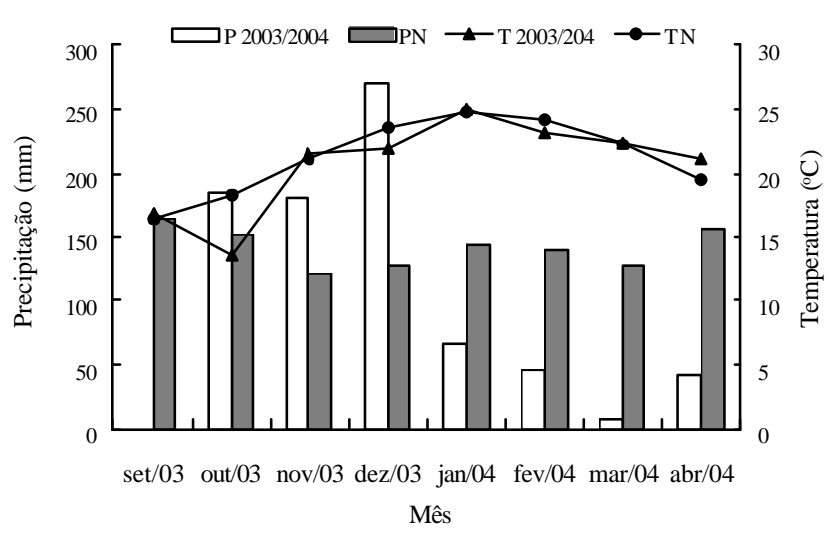

Figura 1 - Precipitação $(P)$ e temperatura média $(T)$ mensal no período experimental e normais regionais ( $\mathrm{PN} ; \mathrm{TN})$. São Sepé, RS. 2003-2004. Fonte: INMET.

as quatro aplicações, no emparelhamento da pastagem e após os três primeiros cortes, foram aplicados 60, 120 e $180 \mathrm{~m}^{3} /$ ha de chorume, que, em quantidade de $\mathrm{N}$, totalizaram 307,$2 ; 614,8$ e $922 \mathrm{~kg} / \mathrm{ha}$, respectivamente. Com o índice de disponibilização de 0,8 no primeiro cultivo (SBCS, 2004), essas quantidades representaram concentração de nitrogênio de 245,7; 491,8 e $737.6 \mathrm{~kg} / \mathrm{ha}$ para as três doses.

O chorume foi aplicado após o corte da pastagem em 15/10/2003 (corte de emparelhamento), 24/11/2003, 10/1/2004 e 25/2/2004. Em 10/4/2004, foi realizado o último corte, quando não foi mais aplicado chorume. As aplicações do fertilizante foram feitas pela manhã, após homogeneização (na própria esterqueira), coleta, transporte até o local do experimento e amostragem para a verificação da densidade. Os cortes foram realizados com roçadeira costal a aproximadamente $7 \mathrm{~cm}$ da superfície do solo. Antes de cada corte, mediu-se a altura da pastagem e demarcou-se uma área de $1 \mathrm{~m}^{2}(0,5 \times 2 \mathrm{~m})$ no centro da parcela para coleta e peso da massa verde. Posteriormente, as parcelas foram roçadas e o restante do material foi retirado com auxílio de ancinhos. Do material vegetal presente na área amostral foram retiradas subamostras de aproximadamente $500 \mathrm{~g}$, que, depois de pesadas, foram colocadas em estufa de ventilação forçada a $70^{\circ} \mathrm{C}$ até peso constante. Depois de secas, as amostras foram pesadas, trituradas em moinho tipo Willey e analisadas quanto aos teores de proteína bruta (PB), fibra em detergente ácido (FDA) e fibra em detergente neutro (FDN), pelo método de espectrometria de reflectância no infravermelho proximal (NIRS), cuja curva de calibração foi desenvolvida pelo Laboratório de Nutrição Animal, do Centro de Pesquisa em Alimentos da Universidade de Passo Fundo. O teor de hemicelulose foi obtido pela diferença entre FDN e FDA. A partir dos dados de altura e MS, calculou-se a densidade do horizonte de colheita (DHC= $\mathrm{kg}$ MS/ha : cm de horizonte), segundo Moliterno (2002), considerando o perfil da pastagem acima da altura de corte $(7 \mathrm{~cm})$. Posteriormente, foram coletadas amostras de solo nas parcelas adubadas com chorume para análise química, segundo metodologia de Tedesco et al. (1995). Foram calculadas a quantidade de $\mathrm{N}$ extraído pela pastagem $(\mathrm{Nextr}=$ $\mathrm{MS} \times$ quantidade de $\mathrm{N}$ na MS) e a recuperação de $\mathrm{N}(\mathrm{Nrec}=$ $100 \times[$ Nextr parcelas fertilizadas - Nextr parcela testemunha/ dose de $\mathrm{N}$ aplicada]), conforme descrito por Primavesi et al. (2004). O cálculo de eficiência do chorume e do $\mathrm{N}$ foi realizado utilizando-se a fórmula: $\mathrm{EC}=\left(\mathrm{MS}_{\mathrm{D} 15, / 30 / 45^{-}}\right.$ $\mathrm{MS}_{\text {testemunha }}$ ): chorume e/ou N.

Os dados foram submetidos à análise da variância, com posterior análise de regressão, utilizando-se o modelo de parcela subdividida no tempo, no qual as doses constituíram a parcela principal e os cortes, as subparcelas. Para comparação das médias obtidas nas datas de cortes, utilizou-se o teste de Tukey a $5 \%$ de significância.

\section{Resultados e Discussão}

A altura aumentou de forma linear de acordo com as doses de chorume (Figura 2); com a maior dose, obteve-se $42 \%(21,1 \mathrm{~cm})$ de acréscimo em relação à testemunha $(14,8$ $\mathrm{cm})$. A produção de MS também respondeu de forma linear ao aumento das doses de chorume, tanto na média dos cortes como na produção total na estação de crescimento (Figura 3), o que representou 42\% (D15), 86,6\% (D30) e $108,6 \%$ (D45) em relação à testemunha.

Com adubação nitrogenada à base de uréia $(200 \mathrm{~kg} / \mathrm{ha}$ de N), Amaral et al. (2006), na região da Campanha do Rio Grande do Sul, obtiveram aumento de $17 \%$ na altura de $94 \%$ na MS (5.420 kg/ha) de uma pastagem natural em relação ao campo não adubado $(2.789 \mathrm{~kg} / \mathrm{ha})$. Considerando a similaridade entre a fisionomia da pastagem deste estudo e a avaliada por esses autores, assim como as condições climáticas, uma vez que os estudos foram realizados no mesmo ano e época, os resultados indicam a validade do uso do chorume suíno para aumentar a produção das pastagens naturais. Durigon et al. (2002) obtiveram melhores respostas na mesma região; com 28 aplicações de chorume suíno sobre pastagem natural durante quatro anos, houve aumento de 44 e $70 \%$ na produção de MS aos 8,3 meses e de 109 e $155 \%$ ao final de 48 meses nas doses de 20 e $40 \mathrm{~m}^{3} / \mathrm{ha} /$ corte, respectivamente, em comparação à pastagem testemunha.

A média anual de produção de MS das pastagens naturais no Sul do Brasil é de $4.000 \mathrm{~kg} / \mathrm{ha} /$ ano ou até menor. Na Depressão Central do Rio Grande do Sul, varia de 841 a $2.018 \mathrm{~kg} / \mathrm{ha}$ (Damé et al., 1999). Portanto, a produção de MS 


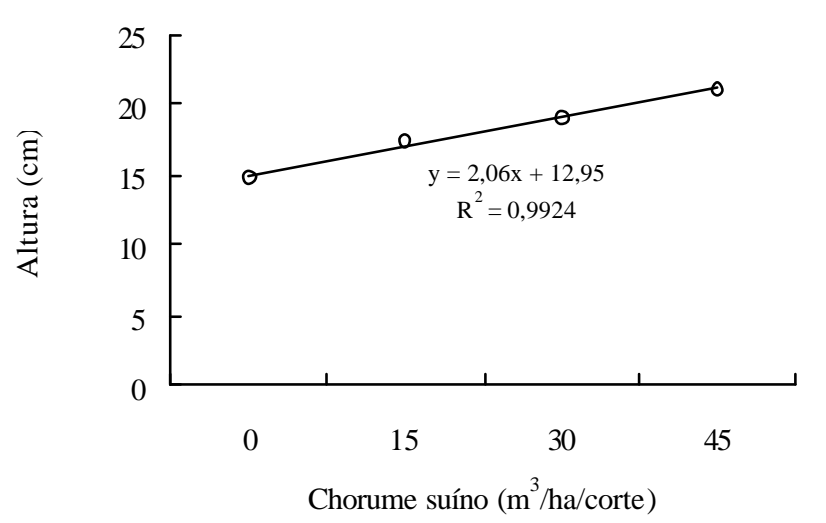

Figura 2 - Altura de uma pastagem natural adubada com chorume suíno.

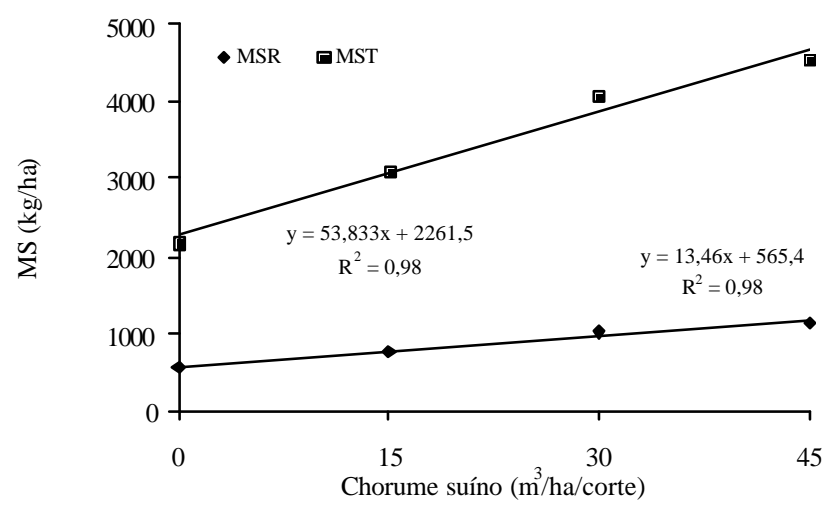

Figura 3 - Produção de MS de uma pastagem natural (MSC = média dos cortes; MST = total dos quatro cortes) adubada com chorume suíno.

de $4.589 \mathrm{~kg} / \mathrm{ha}$ obtida neste trabalho em apenas seis meses e com as restrições hídricas ocorridas indica que é possível dobrar a produção anual com a adubação orgânica, que, muitas vezes, está disponível na propriedade, gerando menores custos.

Na prática, a definição da dose a ser aplicada depende da eficiência de uso do insumo, medida pela produção de $\mathrm{MS} / \mathrm{m}^{3}$ de dejeto aplicado e principalmente pelo custo (Konzen, 2003). Neste estudo, as pastagens não diferiram quanto à eficiência de utilização (média de $15,7 \mathrm{~kg} \mathrm{MS} / \mathrm{ha} / \mathrm{m}^{3}$ de chorume). No entanto, pela similaridade da resposta das duas maiores doses (Figura 4) ao longo do tempo e considerando o risco ambiental dos dejetos, $30 \mathrm{~m}^{3} / \mathrm{ha} /$ cortepode ser considerado valor-referência para as pastagens naturais (Figura 4). O fato de $70 \%$ do $\mathrm{N}$ aplicado em forma de chorume de suínos poder se tornar um poluente (Durigon et al., 2002) sugere cuidado na recomendação de doses mais elevadas em pastagens naturais que não tenham sido sobressemeadas com espécies de elevada produção. Durigon et al. (2002) recomendaram $20 \mathrm{~m}^{3} / \mathrm{ha} /$ corte em pastagem natural a partir de dados de 48 meses após 28 aplicações de chorume suíno.

A quantidade de $\mathrm{N}$ extraída pela pastagem aumentou linearmente de acordo com as doses de chorume, com máximo de 16,15 kg N/ha na média dos cortes (Figura 5), aquém do obtido por Durigon et al. (2002), que estimaram em 0,70 e $1,17 \mathrm{~kg} / \mathrm{ha} /$ dia a extração de $\mathrm{N}$ na MS, com doses de 20 ou $40 \mathrm{~m}^{3}$, o que representou 32 e $53 \mathrm{~kg} \mathrm{~N} / \mathrm{ha}$ em um período de 45 dias. Primavesi et al. (2004), em pastagem de Cynodon sp. adubada com N mineral (200 kg/ha), obtiveram 31 a $146 \mathrm{~kg} \mathrm{~N} / \mathrm{ha}$.

Os tratamentos não diferiram quanto à eficiência de nitrogênio, que foi de apenas $3,1 \mathrm{~kg} \mathrm{MS} / \mathrm{ha} / \mathrm{kg}$, de modo que a recuperação média de nitrogênio foi de $4,5 \%$ e indica que a demanda das plantas foi muito pequena, em decorrência da estiagem na região (Figura 1). Em pastagem natural da mesma região, Amaral et al. (2006) e Cunha et al. (2001), com fertilizante nitrogenado mineral, obtiveram 13,1 e 8,94 kg $\mathrm{MS} / \mathrm{ha} / \mathrm{N}$, respectivamente. Durigon et al. (2002) verificaram aos 48 meses após a aplicação de 28 doses de chorume suíno, em pastagem natural, aproveitamento de 29 e $23 \%$

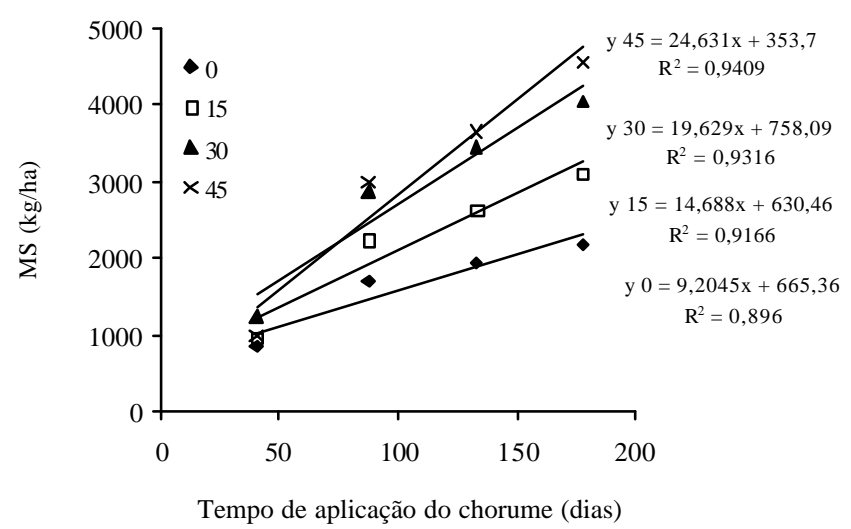

Figura 4 - Produção acumulada de MS de uma pastagem natural adubada com chorume suíno $\left(0,15,30\right.$ e $45 \mathrm{~m}^{3} / \mathrm{ha} /$ corte).

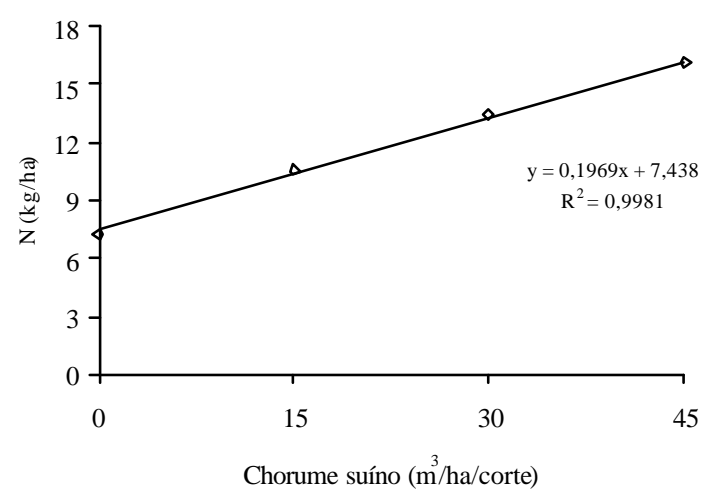

Figura 5 - Extração de nitrogênio de uma pastagem natural adubada com chorume suíno, média de três cortes. 
para doses de 20 e $40 \mathrm{~m}^{3} / \mathrm{ha}$. Segundo esses autores, é importante que o chorume seja aplicado em pastagens sob condições climáticas e em estádio fenológico que exijam elevada demanda de nitrogênio para que esse nutriente seja eficientemente absorvido. Como a disponibilidade dos nutrientes em chorumes e estercos é mais imprevisível que em adubos minerais, o ideal seria compatibilizar a época da aplicação com a condição em que as culturas estivessem em condições de máxima absorção dos nutrientes (Veltholf et al., 2000). Neste estudo, a eficiência da adubação teria sido superior se as condições pluviométricas tivessem sido favoráveis, o que possibilitaria melhor crescimento das plantas e maior demanda. As maiores produções de MS foram obtidas nos dois primeiros cortes (Figura 6), quando as condições de pluviosidade foram normais. Nos dois últimos cortes, a produção média de MS foi $140 \%$ inferior à obtida nos dois primeiros cortes, portanto, a deficiência hídrica foi determinante dessa menor produção de forragem.

Os efeitos da condição hídrica refletiram também na DHC, que, na ocasião do terceiro corte, correspondeu à metade da verificada no primeiro corte. Assim, apesar de a altura e o perfil da pastagem terem sido inferiores nos dois primeiros cortes, a densidade da pastagem foi maior. Ao final da estação, a maior altura da pastagem não ocasionou maior produção, em virtude da condição fenológica das espécies estivais, em final de maturação e início de dormência. Os valores da DHC podem ser considerados muitos bons ( $140 \mathrm{~kg} / \mathrm{ha} / \mathrm{cm}$ no primeiro corte). Moliterno (2002), no Uruguai, estimaram em mesclas de aveia (Avena spp.) e leguminosas hibernais (Trifolium spp.) 25,8 e 50,9 kg $\mathrm{MS} / \mathrm{cm} / \mathrm{ha}$, considerando apenas as espécies cultivadas, e $91,2 \mathrm{~kg} / \mathrm{MS} / \mathrm{cm} / \mathrm{ha}$, quando as ervas daninhas foram incorporadas à mistura. Esse resultado indica que a pastagem natural, em condições climáticas favoráveis como no início

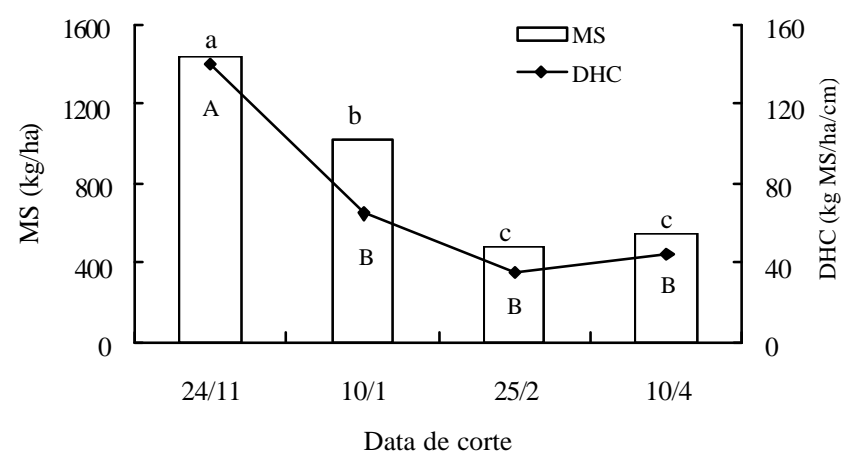

Figura 6 - Produção de MS e densidade do horizonte de colheita (DHC) de uma pastagem natural adubada com chorume suíno.

Médias seguidas de mesma letra (minúscula = MS; maiúscula $=$ $\mathrm{DHC})$ não diferem $(P>0,05)$ pelo teste Tukey. das avaliações, apresenta elevada densidade de afilhos e folhas. Nos dois últimos cortes, a redução da DHC foi de 68 a $75 \%$ em relação ao primeiro corte.

Os teores de $\mathrm{PB}$ da forragem não variaram entre as doses de chorume ( $8,1 \%$, na média). Silveira et al. (2005), em pastagens naturais da Campanha do Rio Grande do Sul, estimaram entre 11 e 14,8\% de PB. Siewerdt et al. (1995), em campo nativo adubado com doses crescentes de $\mathrm{N}$ mineral, obtiveram entre 7,9 e 12,5\% de PB com aplicação de N de 100 e $600 \mathrm{~kg} / \mathrm{ha}$. Ressalta-se que, para elevação dos teores de $\mathrm{N}$ no tecido, são necessárias doses superiores às necessárias para o aumento na produção de MS. Cunha et al. (2001), em trabalho realizado em Pelotas, verificaram aumento de $24,4 \%$ no teor de PB de um campo nativo adubado com doses crescentes de nitrogênio. Entretanto, os teores foram baixos, de $9,1 \%$ na MS da pastagem adubada com $200 \mathrm{~kg} \mathrm{~N} /$ hae de 7,33\% com $50 \mathrm{~kg} \mathrm{~N} / \mathrm{ha}$. Esses autores concluíram que a maior dose de nitrogênio testada não foi suficiente para determinar o máximo teor de $\mathrm{PB}$ na MS. De qualquer modo, os valores encontrados neste estudo estão dentro do mínimo necessário para bovinos adultos em pastejo (Minson, 1981). Além disso, a pastagem produzida com a adubação orgânica neste estudo poderia ser utilizada inclusive para feno (Siewerdt et al., 1995).

Os teores FDA foram afetados pelos tratamentos e foram pouco menores $(\mathrm{P}<0,05)$ na MS da pastagem adubada, entre 41,8\% (D45) e 43,5\% (D15), em relação à testemunha $(45,6 \%)$. O período de colheita afetou significativamenteo teor de FDN e de hemicelulose, que aumentaram progressivamente com o avanço da estação de crescimento (Figura 7). Na média geral, o valor de FDN (69\%) foi inferior ao verificado (72-80\%) por Silveira et al. (2005) em ampla pesquisa sobre a qualidade de pastagens naturais. A variação do conteúdo de fibra pode ser atribuída às alterações fenológicas das espécies componentes da pastagem, que eram basicamente estivais e, no final do verão, estavam em fase final de florescimento.

Ao final do experimento, as análises do solo revelaram expressivo aumento nos teores de $\mathrm{P}$ e $\mathrm{K}$ nas parcelas adubadas com chorume (Figura 8), em relação à testemunha, comprovando o valor desse resíduo como fertilizante. As alterações nos atributos químicos do solo também foram descritas por Ceretta et al. (2003) em estudo sobre o uso de chorume em pastagem natural. Esses autores evidenciaram elevada concentração de P na camada superficial do solo, com aumentos de $580 \%$ aos 8,3 meses e de $6.710 \%$ aos 48 meses de aplicação com chorume. Além disso, verificaram diminuição na saturação de $\mathrm{Al}$ e elevação nos teores de $\mathrm{Ca}$ e $\mathrm{Mg}$. Neste trabalho, obteve-se aumento de $164 \%$ para K, $950 \%$ para $\mathrm{P}, 100 \%$ para $\mathrm{Ca}$ e $56 \%$ para $\mathrm{Mg}$. 


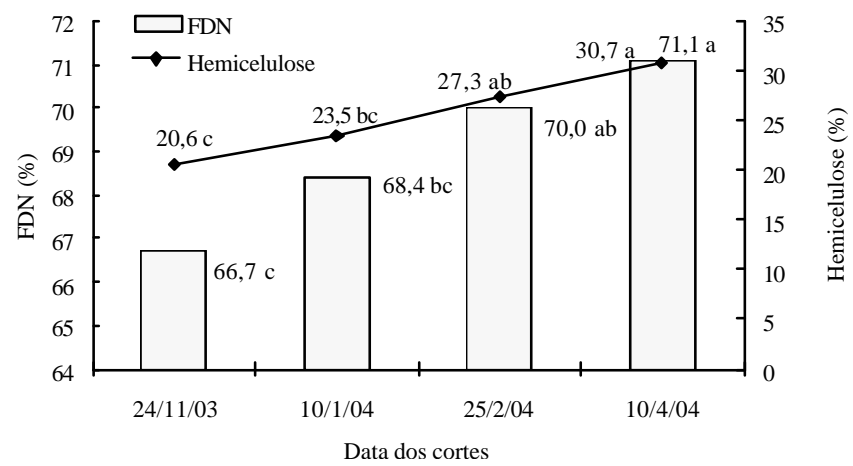

Figura 7 - Teor de fibra em detergente neutro (FDN) e hemicelulose de uma pastagem natural adubada com chorume suíno.

Médias seguidas de mesma letra não diferem $(P>0,05)$ pelo teste Tukey.
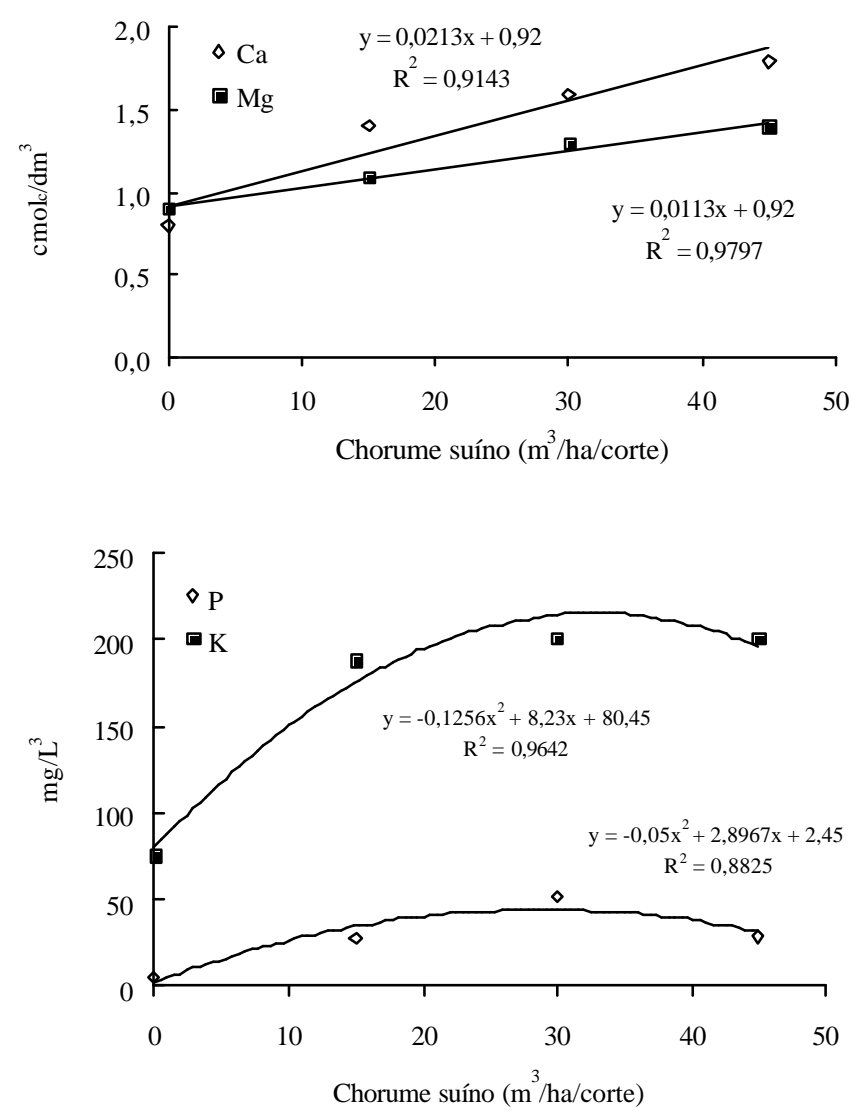

Figura 8 - Concentração de minerais no solo de uma pastagem natural após quatro aplicações de chorume suíno.

Segundo Durigon et al. (2002), a aplicação de esterco líquido de suínos representa contínuo aporte de fósforo no solo, uma vez que aproximadamente dois terços desse mineral são encontrados na forma não-solúvel em água e combinados com compostos orgânicos de natureza variada. O potássio, no entanto, encontra-se na forma solúvel e possui efeito residual curto.
Trabalhos com essa abordagem desafiam a integração das áreas de Zootecnia envolvidas na fertilidade de solo, tendo em vista a implicação ambiental do uso de dejetos suínos. Como descrito por Seganfredo (1999), a produtividade das culturas a curto prazo e a facilidade da aplicação na propriedade não são critérios suficientes para avaliar as perspectivas de sustentabilidade de sistemas que utilizam dejetos de suínos como fertilizantes.

\section{Conclusões}

A aplicação de chorume suíno é uma alternativa para aumentar a produção de pastagens naturais. A aplicação de $30 \mathrm{~m}^{3} /$ ha após cada corte ou pastejo pode ser um valorreferência para pastagens naturais do Rio Grande do Sul e necessita ser validada com mais estudos. As aplicações de chorume devem ser realizadas em épocas em que as condições climáticas favoreçam a produção de forragem, impondo maior demanda na absorção de nutrientes. O aumento das concentrações de potássio e fósforo no solo indica a necessidade de avaliação periódica das características do solo para eventual alteração no manejo.

\section{Literatura Citada}

AMARAL, D.C.; SCHEFFER-BASSO, S.M.; FONTANELI, R.S. Efeito da fertilização nitrogenada na produção e composição química de uma pastagem natural. Agrociencia, v.10, n.1, p.1724, 2006.

CERETTA, C.A.; DURIGON, R.; BASSO, C.J. et al. Características químicas de solo sob aplicação de esterco líquido de suínos em pastagem natural. Pesquisa Agropecuária Brasileira, v.38, n.6, p.729-735, 2003.

CUNHA, M.K.; SIEWERDT, L.; SILVEIRA, P. et al. Doses de nitrogênio e enxofre na produção e qualidade da forragem de campo natural de planossolo no Rio Grande do Sul. Revista Brasileira de Zootecnia, v.30, n.3, p.651-658, 2001.

DAMÉ, P.R.V.; ROCHA, M.G.; QUADROS, L.F.; PEREIRA, C.F.S. Estudo florístico de pastagem natural sob pastejo. Revista Brasileira de Agrociência, v.5, p.45-49, 1999.

DURIGON, R.; CERETTA, C.A.; BASSO, C.J. et al. Produção de forragem em pastagem natural com o uso de esterco líquido de suínos. Revista Brasileira de Ciência do Solo, v.26, p.983992, 2002.

EDMEADES, D.C. The long-term effects of manures and fertilizers on soil productivity and quality: a review. Nutrient cycling in agrosystems, v.66, n.2, p.165-180, 2003.

INSTITUT O BRASILEIRO DE GEOGRAFIA E ESTATÍSTICA IBGE [2007]. Censo Agropecuário de 1995-1996. Disponível em: http://www.ibge.gov.br/home/estatistica/economia/agropecuaria/ censoagro/brasil/tabela1brasil.htm. Acesso em: 28/5/2007.

KONZEN, E.A. Fertilização de lavoura e pastagem com dejetos de suínos e cama de aves. Sete Lagoas: Embrapa Milho e Sorgo, 2003. 19p. (Informe Técnico)

MARASCHIN, G.E.; JACQUES, A.A. Grassland opportunities in the subtropical region of South America. In: BAKER, M.J. (Ed.). Grasslands of our world. Wellington: SIR Publishing, 1993. p.747-752.

MEDEIROS, L.T.; REZENDE, A.V.; VIEIRA, P.F. et al. Produção e qualidade da forragem de capim-marandu fertiirrigada com 
dejetos líquidos de suínos. Revista Brasileira de Zootecnia, v.36, n.2, p.309-318, 2007.

MINSON, D.J. Effects of chemical and physical composition of herbage eaten upon intake. In: HACKER, J.B. (Ed.). Nutritional limits to animal production from pastures. St. Lucia: CSIRO, 1981. p.167-182.

MOLITERNO, E.A. Variables básicas que definen el comportamiento productivo de mezclas forrajeras en su primer año. Agrociencia, v.6, n.1, p.40-52, 2002.

MORENO, J.A. O clima do Rio Grande do Sul. Porto Alegre: Secretaria da Agricultura, 1961. p.41.

PRIMAVESI, A.C.; PRIMAVESI, O.; CORRÊA, L.A. et al. Adubação nitrogenada em capim-coastcross: efeitos na extração de nutrientes e recuperação aparente do nitrogênio. Revista Brasileira de Zootecnia, v.33, n.1, p.68-78, 2004.

SEGANFREDO, M.A. Os dejetos de suínos são um fertilizante ou um poluente do solo? Cadernos de Ciência \& Tecnologia, v.16, n.3, p.129-141, 1999.
SIEWERDT, L.; NUNES, A.P.; SILVEIRA, P. Efeito da adubação nitrogenada na produção e qualidade da matéria seca de um campo nativo de planossolo no Rio Grande do Sul, Pelotas-RS. Revista Brasileira de Agrociência, v.1, n.3, p.157-162, 1995. SILVEIRA, V.C.P.; VARGAS, A.F.C.; OLIVEIRA, J.C. et al. Qualidade da pastagem nativa obtida por diferentes métodos de amostragem e em diferentes solos na Apa do Ibirapuitã Ciência Rural, v.35, n.3, p.582-588, 2005.

SOCIEDADE BRASILEIRA DE CIÊNCIA DO SOLO - SBCS. Manual de adubação e calagem para os Estados do Rio Grande do Sul e de Santa Catarina. Porto Alegre: Comissão de Química e Fertilidade do Solo, 2004. 400p.

TEDESCO, M.J.; GIANELLO, C.; BISSANI, C.A. et al. Análises de solo, plantas e outros materiais . Porto Alegre: Universidade Federal do Rio Grande do Sul, 1995. 174p. (Boletim Técnico de Solos, 5)

VELTHOF, G.L.; BANNINK, A.; OENEMA, O. et al. Relationships between animal nutrition and manure quality. Wageningen: Alterra, 2000. 44p. 